\title{
"Guerra ao tráfico", violência policial e os limites da democracia brasileira
}

\author{
Livia De Tommasi ${ }^{1}$
}

\begin{abstract}
ALVES, Maria Helena Moreira e EVANSON, Philip. Vivendo no fogo cruzado: moradores de favelas, traficantes de droga e violência policial no Rio de Janeiro. São Paulo: Editora da Unesp, 2013, 392 p.
\end{abstract}

O livro de Maria Helena Moreira Alves e Philip Evanson é um livro de entrevistas, que dá voz às denúncias sobre as violências cometidas pelas forças policiais no Rio de Janeiro, com o intuito de pressionar os políticos brasileiros para que modifiquem as formas violentas de atuação no campo da segurança pública, em defesa do estado de direito. É, portanto, um livro engajado, situado num momento histórico preciso: por ocasião da realização dos XV Jogos Pan-americanos no Rio de Janeiro, em 2007, as forças militares ocuparam algumas favelas. Foi realizada uma imponente operação de mais de 1300 policiais e militares no Complexo do Alemão, que resultou na morte de, pelo menos, 19 moradores. É a época do segundo mandato do governo Lula, em nível federal, e do primeiro de Sergio Cabral como governador do Estado de Rio de Janeiro, momento de acirramento da chamada "guerra ao tráfico", mas também de grandes expectativas reformistas depositadas na criação do Programa Nacional de Segurança com Cidadania (Pronasci).

Maria Helena Moreira Alves, cientista política aposentada da Universidade Estadual do Rio de Janeiro (UERJ), fez seus estudos nos Estados Unidos, onde também lecionou. Irmã de Marcio Moreira Alves, jornalista e deputado federal cujo mandado foi um dos primeiros a ser cassado pela ditadura logo após a proclamação do Ato Institucional 5, Maria Helena pertence a uma importante família de políticos brasileiros. É autora de um livro de referência sobre a ditadura militar, Estado e oposição no Brasil (1964-1984) (Petrópolis: Vozes, 1984; Bauru: Edusc, 2005), resultado de sua tese de doutoramento no Massachusetts

I Professora do Departamento de Sociologia e do Programa de Pós-Graduação em Cultura e Territorialidades da Universidade Federal Fluminense (UFF, Niterói, RJ, Brasil). E-mail: livia.detommasi@gmail.com 
Institute of Technology (MIT), uma pesquisa onde periodiza e analisa o processo de institucionalização do Estado de Segurança Nacional. Por sua vez, Peter Evanson é professor emérito de História na Universidade de Temple (Filadélfia, Pensilvânia), nos Estados Unidos. O livro foi publicado inicialmente pela Temple University Press, em 2011, e sucessivamente traduzido e publicado no Brasil. É, portanto, um livro escrito principalmente para o público norte-americano.

Os autores puderam valer-se de seu prestígio pessoal para conseguir entrevistar (entre 2007 e 2008), sobre um tema tão espinhoso como a segurança pública, todos os homens políticos brasileiros mais importantes responsáveis pelas políticas de segurança. No governo federal: o então Presidente Lula; o ex-Presidente Fernando Henrique Cardoso; o Ministro da Justiça, Tarso Genro; o Secretário Nacional de Segurança Pública, Ricardo Balestreri, o chefe da Secretaria de Direitos Humanos, Paulo Vannuchi. No governo estadual do Rio de Janeiro: o governador Sergio Cabral; o Secretário de Segurança Pública, Mariano Beltrame; Henrique Oliveira Vianna, coordenador do Pronasci; Antonio Carlos Carballo Blanco, oficial da Polícia Militar; além de um pesquisador e consultor não-identificado.

Mas, e essa é a principal qualidade do livro e o seu principal interesse, os autores não se limitam a entrevistar somente gestores e políticos. Pelo contrário, começam ouvindo moradores de algumas favelas do Rio de Janeiro, professores nas escolas situadas no "fogo cruzado", ou seja, nos lugares onde acontece a "guerra ao tráfico", onde os moradores vivem no meio dos tiroteios, obrigados a adequar seu cotidiano às exigências e perigos de viver num território "em guerra", guerra provocada pelas incursões policiais que deixa marcas de balas nas paredes e marcas profundas do medo, impotência, revolta na memória de adultos e crianças; guerra que, com coragem e acuidade, os autores apresentam como uma continuidade da guerra contra o "inimigo interno" decretada pela ditadura militar. As crianças também foram ouvidas, em oficinas onde era proposto a elas desenhar para expressar suas vivências e sentimentos com relação à polícia. Entrevistaram-se, também, lideranças comunitárias de favelas; favelas onde os autores se inseriram e ganharam a confiança dos moradores, contando com a ajuda de movimentos sociais, especificamente da Rede de Comunidades e Movimentos contra a Violência (que reúne sobreviventes e familiares de vítimas de violência policial e militar e militantes populares de direitos humanos), e de organizações não-governamentais.

Cabe lembrar que, em 2007, as imagens da invasão policial no Complexo do Alemão, que resultou na morte de 19 moradores, dentre os 
quais algumas crianças, foram difundidas por redes de televisão internacionais. Um relatório elaborado pela Secretária Nacional de Direitos Humanos admitiu que, na operação, houve execuções. O Secretário de Segurança Pública do Estado do Rio de Janeiro, Mariano Beltrame, questionou e desqualificou o relatório do governo federal. Mas as pressões internacionais motivaram a chegada, no mesmo ano, de um relator da ONU especializado em execuções extrajudiciais, sumárias e arbitrárias, o qual visitou o Complexo do Alemão para indagar os fatos acontecidos; o relator concluiu denunciando a arbitrariedade da operação militar e formulando uma série de recomendações para o governo brasileiro (reproduzidas no final do livro, p. 340-343). Esse é, portanto, o clima político, social e midiático em que o texto do livro foi gestado. Os autores quiseram ressaltar e ampliar o alcance daquelas denúncias.

Por outro lado, o livro foi publicado no Brasil no contexto de outros acontecimentos significativos no âmbito da segurança pública: em junho de 2013, as polícias utilizaram métodos de repressão violenta, reservados geralmente para as incursões em favelas e periferias (ou seja, onde moram pobres, pretos e, supostamente, "bandidos") para enfrentar os protestos que ocupavam as ruas de muitas cidades do país, por ocasião de outro evento esportivo importante, a realização da Copa das Confederações, que precedeu a realização da Copa do Mundo de 2014. Nesses protestos, participaram sobretudo jovens, estudantes, moradores das regiões nobres da cidade. O lançamento do livro teve uma ampla divulgação midiática. A autora participou de programas televisivos, como o do Jô Soares, e concedeu numerosas entrevistas, nas quais denunciou: "A polícia mata mais agora do que na ditadura militar". Acusação forte, que teve uma repercussão significativa no contexto dos movimentos de protesto. Afirma Maria Helena, em entrevista para o jornalista Yan Boechat:

Estamos chegando a um ponto onde as coisas estão passando de qualquer limite do aceitável e as pessoas da classe média estão se dando conta de que há uma política de extermínio e que as forças do estado estão atuando como em uma ditadura militar, sem respeitar nenhum direito constitucional. (...) Nessas manifestações isso ficou claro. Os desrespeitos aos direitos civis foram tremendos e, pela primeira vez, atingiram não só os pobres e negros, mas também os filhos da classe média. E de repente eclodiu a indignação. (...) Vai ter que ter uma mudança na visão da classe alta, entender que é impossível viver em um país em que 
a democracia só existe nos bairros nobres e o fascismo impera na favela. ${ }^{2}$

As entrevistas com os moradores das favelas publicadas no livro são testemunhos igualmente fortes, repletos de denúncias que podem colocar em risco a vida das pessoas que as pronunciam. Porque, e isso fica claro na leitura dos relatos, os moradores de favela não têm em quem confiar, não têm um Estado ou qualquer outra autoridade que os defenda. Estão sozinhos e precisam aprender a viver no meio do fogo cruzado, entre a máquina de guerra da polícia do Estado e o poder das armas dos comandos do tráfico.

Esse é, portanto, um livro de denúncias. Mais do que uma pesquisa acadêmica, trata-se de uma ampla reportagem sobre os abusos cometidos pelas forças policiais que invadem as favelas. A escolha por esse tipo de política por parte das autoridades do Estado do Rio de Janeiro é fortemente criticada. Chama atenção que, ao mesmo tempo em que os moradores acusam os "bandidos" por estar provocando a situação de guerra em que estão constrangidos a viver, fazendo continuamente referência ao sentido comum que contrapõe "bandidos" e "trabalhadores", suas falas reiteram a ideia de que a situação de insegurança e a violência são provocadas muito mais pelas incursões armadas dos policiais do que pela presença dos traficantes. As afirmações de professoras são contundentes:

“(...) quando os bandidos estão sozinhos, não atiram na escola, mas quando o poder constituído estabelece um enfrentamento, usando a escola como um escudo, os policiais entram no pátio e depois fazem um tiroteio com duas escolas no meio" (p. 55);

"É um pensamento bélico. (...) Me parece que é uma visão bem excludente, fascista mesmo, porque os pobres são todos inimigos e todos considerados bandidos. Então não importa se é uma escola, se tem mil crianças lá dentro, porque todos são marginais" (p. 57); "O lema da escola é 'somente por hoje vamos sobreviver" (p. 59); "Não existe uma polícia de inteligência, de investigação, então eles só sabem mesmo é atirar. (...) Outro dia mataram um barbeiro aqui quando estava no trabalho. Falaram que era marginal. Não era!" (p. 61);

2 A entrevista está disponível no endereço eletrônico: https://medium.com/@Yanboechat/ a-policia-mata-mais-hoje-do-que-na-ditadura-militar-az695eac61ze Acesso em: 29 jul. 2014. 
“(...) o bandido acaba tendo mais respeito da comunidade do que a polícia. (...) a polícia não sabe quem é e quem não é bandido, mas trata todo mundo como se fosse. Então a comunidade acaba ficando contra" (p. 71).

As lideranças, por sua vez, denunciam com força que essas violações não acontecem por acaso, mas respondem a um "programa lento, porém contínuo, de genocídio contra as comunidades" (p. 162). "Os ricos querem paz para continuar ricos. Nós queremos paz para continuar vivos" (p. 189).

Os detalhes com os quais os entrevistados descrevem a violência provocada pelas invasões policiais - especificamente pelo caveirão que entra na favela atirando a esmo, cruza o portão de uma escola instalandose no pátio, ameaçando os moradores com expressões do tipo "sai da frente, eu vou sugar sua alma", tocando uma música sinistra que fica marcada na memória das crianças como o símbolo do terror - são assustadores e indignam qualquer leitor.

As consequências das incursões violentas das forças policiais nos territórios das favelas, as mortes que provocam, a entrada do caveirão na escola, o comportamento dos policiais que desde ali, protegidos, covardemente desrespeitam os direitos dos moradores, tudo isso é uma denúncia que os autores levam para as autoridades, cujas entrevistas são colocadas na última parte do livro. Lucidamente os autores atribuem as causas da violência na "cidade maravilhosa" à extrema concentração de renda, à "obsessão da mídia em estabelecer uma narrativa de guerra da polícia contra traficantes e criminosos" (p. 23), à escolha por parte dos governantes locais de uma política de enfrentamento militar e à herança da ditadura que permeia as forças policiais e militares do país.

Os problemas históricos da polícia brasileira, do ponto de vista da organização institucional, da hierarquia, dos baixos salários, da difusão da corrupção, da falta de preparo, são colocados num capítulo do livro onde os autores repercorrem as etapas mais significativas das ações no campo da segurança pública no Rio de Janeiro, desde a ditadura militar até a instalação recente das Unidades de Polícia Pacificadoras (UPPs). Narram, inclusive, as origens das milícias. O governador Sergio Cabral é apontado como o responsável pela escolha de uma política de enfrentamento que provocou (e continua provocando) muitas mortes de moradores. As taxas de homicídios denunciam um número de mortes violentas muito superior à média nacional, enquanto se sabe que baixo a denominação de "auto de resistência" são camuflados muitos assassinados cometidos por policiais. 
Mas, se à política de confronto é contraposta a política centrada na criação de uma "polícia de proximidade", na aliança entre as diferentes esferas de governo que deveria levar a uma progressiva desmilitarização da polícia militar, no investimento em equipamentos para aprimorar o sistema de investigação, política proposta pelo Pronasci, a falência daquela tentativa de reforma deveria ser melhor analisada e compreendida. Hoje, é a falência do modelo de intervenção proposto com a implantação das UPPs que está na ordem do dia, programa que propôs, em teoria, "retomar os territórios" e estabelecer uma "polícia comunitária” e que, na prática, impôs a ocupação militar e o controle ostensivo resultando, denuncia Maria Helena Moreira Alves ${ }^{3}$, na instalação de um estado de exceção nas favelas.

Considerado que todos os gestores e políticos entrevistados citam o Pronasci ${ }^{4}$ como a grande proposta de reforma, que deveria provocar supostamente uma transformação profunda nos rumos da política de segurança pública, é inevitável se perguntar: como e quando acabou essa expectativa?; como e o que provocou o abandono prematuro do programa? Curiosamente, não existe, até hoje, nenhuma pesquisa acadêmica de fôlego sobre o programa, apesar de ele ter sido o programa de segurança pública com o maior volume de investimentos na história brasileira: 7 bilhões de reais ${ }^{5}$. Durante alguns anos, foi também o programa com o maior volume de recursos do governo federal, sobre o qual se apoiaram

3 “UPPs são estado de exceção e ameaçam a democracia, diz socióloga”, entrevista publicada no dia 25/o8/2013 na Folha de S. Paulo. Disponível em: http://wwwı.folha. uol.com.br/cotidiano/2013/o8/1331602-upps-sao-estado-de-excecao-e-ameacamdemocracia-diz-sociologa.shtml Acesso em: 29 jul. 2014.

4. Sobre as expectativas colocadas no Pronasci, ver a entrevista com Ricardo Balestreri, um dos gestores nacionais do programa, publicada em 2012, onde ele conclui: "Foi realmente um período de ouro para a segurança pública do Brasil. Não foi perfeito, mas foi a melhor coisa que aconteceu na história da segurança pública". Disponível em: http://segurancaedemocracia.wordpress.com/2012/o3/27/ pronasci-foi-a-grande-luz-de-esperanca-na-seguranca-publica/ Acesso em: 29 jul. 2014 .

5 O Pronasci foi lançado no segundo mandado do Presidente Lula, em 20o7, por meio de uma medida provisória, e previa o investimento de R\$6,707 bilhões até o fim de 2012, em um conjunto de 94 ações, que deveriam envolver 19 ministérios, em intervenções articuladas com estados e municípios. Uma descrição precisa da política nacional de segurança pública até 2007 , incluindo uma apresentação crítica do Pronasci, que aponta também seus limites assim como os elementos de continuidade com o Plano Nacional de Segurança Pública, lançado no começo do primeiro governo Lula, foi realizada por Luiz Eduardo Soares; ver SOARES, Luiz Eduardo. A Política Nacional de Segurança Pública: histórico, dilemas e perspectivas. Estudos avançados, São Paulo, v. 21, n. 61, p. 77-97, dez. 2007. Disponível em: http://goo.gl/OKEL7g. Acesso em: 29 jul. 2014.

DOI: http://dx.doi.org/10.1590/So103-401420070003000o6. 
muitas iniciativas em diferentes áreas, como por exemplo o maior programa de investimento público na área de Economia Solidária, o Rio Ecosol, desenvolvido pela Prefeitura do Rio de Janeiro em quatro territórios "carentes" da cidade 6 .

O Pronasci contemplava um leque muito amplo de projetos, dentre os quais, notadamente, a construção de novos presídios, a reforma dos velhos, a realização de cursos de formação para policiais que receberam, em troca, uma bolsa-formação para complementar seus salários. Investimentos em programas sociais de prevenção e envolvimento da comunidade, como os Territórios da Paz, o Mulheres da Paz e o Protejo ${ }^{7}$. O Pronasci se propusera a gerir o Sistema Único de Segurança Pública (SUSP), que deveria integrar as ações de Municípios, Estados e governo federal, nos moldes do que foi realizado no âmbito da saúde com a criação do SUS (Sistema Único de Saúde). O que provocou o abandono do programa sobre o qual tinham sido depositadas tantas expectativas? As ocorrências de desvio de recursos? O fato de que o orçamento destinado a complementar o salário dos policiais engoliu o orçamento do programa? O fracasso da aposta no protagonismo dos Municípios para a criação e gestão de um novo modelo de segurança pública? Algumas questões centrais, cuja criticidade é discutida há muito tempo no Brasil: a necessidade de aumentar o salário dos policiais, para que não sejam motivados a procurar uma complementação necessária via envolvimento em ações criminosas; a urgência de reformular o pacto federativo, permitindo ao governo federal assumir um papel regulador e assim provocar reformas em escala nacional, dando maior autonomia aos municípios, onde supostamente deveria ser gestado um novo modelo de intervenção centrado na polícia de proximidade; a desconstitucionalização da polícia. A

6 COSTA, Marcelo Henrique da; CASTILHO, Sergio Rodrigues. Desenvolvimento econômico solidário e Segurança pública na cidade do Rio de Janeiro: estratégias para a ação. Mercado do Trabalho, Brasília, IPEA, n. 46, p. 57-61, fev. 2011. Disponível em: http://www.ipea.gov.br/agencia/images/stories/PDFs/mercadodetrabalho/ bmt46_6_econ_desenvolvimento.pdf. Acesso em: 29 jul. 2014.

7 A criação de Territórios da Paz deveria significar a integração territorial de ações de prevenção, repressão e assistência, após a ocupação pelas forças militares dos territórios controlados pelos comandos do tráfico. Mulheres da Paz objetiva a capacitação de mulheres atuantes na comunidade para que se constituam como mediadoras sociais. Protejo (Proteção de jovens em território vulnerável) seleciona e acompanha jovens entre 15 e 24 anos em situação de risco ou vulnerabilidade familiar e social, egressos do sistema prisional ou cumprindo medidas socioeducativas, com vistas à desenvolver percursos formativos para a promoção da cidadania, direitos humanos e qualificação profissional. Fonte: portal do Ministério da Justiça, http://portal.mj.gov.br/data/Pages/MJF45553ABıPTBRNN Acesso em: 29 jul. 2014 . 
submissão da Polícia Militar ao Exército é um entrave intransponível, que impede romper com a militarização da polícia e os laços de lealdade dos comandos militares estaduais. Os depoimentos dos responsáveis pela gestão das políticas de segurança em nível federal mencionam sua impotência quando se trata de influir sobre a atuação das forças da polícia militar. O Pronasci tentou provocar mudanças via liberação condicionada de recursos. Mas, colocam os autores Maria Helena Moreira Alves e Philip Evanson, assim como um especialista da área como Luiz Eduardo Soares $^{8}$, a vontade, aliás, a ousadia política é fundamental quando se trata de romper com o legado histórico das forças armadas no Brasil.

Outras questões surgem analisando a proposta de gestão do programa. O desenho previa sua efetivação via contratação de uma rede de consultores que atuavam como mediadores entre a esfera federal e as esferas municipais e estaduais, responsáveis por "vender" a proposta para estados e municípios e cuidar de sua implantação em nível local. Gabinetes de Gestão Integrada Municipal (GGIM) deveriam, nas intenções, cuidar da necessária integração das ações entre as distintas forças de segurança e promover a inclusão dos representes da sociedade civil na discussão das políticas de segurança. Racionalizar, integrar e democratizar a gestão, acabar com a multiplicidade de funções e a esquizofrenia dos comandos são desafios sempre mencionados nas intenções programáticas dos governos. Sua efetiva realização, no entanto, sempre é motivo de fortes críticas.

Em definitivo, Vivendo no fogo cruzado é um livro apaixonado, preocupado com a sustentação do estado democrático. Se a "guerra ao tráfico" é uma continuidade da guerra ao "inimigo interno" da ditadura, se o mito das "classes perigosas", a herança do escravagismo, a atitude racista têm raízes profundas na sociedade brasileira, denunciar e lutar pelo fim dos autos de resistência, das arbitrariedades e violências cometidas pelas forças policiais, pelo fim do assassinato de jovens negros, pobres e moradores de favelas, denunciar e resistir à instauração de um estado de exceção é um atitude urgente e necessária por parte de todos os cidadãos preocupados com a democracia.

DOI: http://dx.doi.org/10.11606/issn.2316-901X.v0i59p397-404

8 SOARES, Luiz Eduardo. A Política Nacional de Segurança Pública: histórico, dilemas e perspectivas. Estudos avançados, São Paulo, v. 21, n. 61, p. 77-97, dez. 2007. Disponível em: http://goo.gl/OKEL7g. Acesso em: 29 jul. 2014. DOI: http://dx.doi.org/10.1590/So103-4014,2007000300006. 